\title{
General Equilibrium Theory in Economics And Beyond
}

\author{
Mohamad Rilwan ${ }^{1}$, Agra T. Wijeratne ${ }^{2}$ \\ ${ }^{1}$ No 25/69 D1, Ragasingha Road, Mabola, Wattala, Sri Lanka \\ ${ }^{2}$ Department of Physics, University of Sri Jayewardenepura, Sri Soratha Mawatha, Nugegoda, Sri Lanka \\ ${ }^{1}$ rilwan.physics@gmail.com ,2agraw@sjp.ac.lk
}

\begin{abstract}
The General equilibrium theory tries to show how and why all free markets tend toward equilibrium in the long run. However, what is meant by equilibrium in this paper is more from a thermodynamical point of view. In order to understand the actual situation, it is necessary to study open systems which are complex. In physics, such a behavior in a complex system can be explain by using Non Equilibrium Thermodynamics. A system is able to selforganize and sustain itself away from equilibrium. Economic systems may fluctuate around a particular point. To sustain it far from the equilibrium state, it needs to degrade more energy and materials. In this study, the energy consumption patterns of Sri Lanka and USA are discussed. The pattern concerning Sri Lanka is close to the model proposed here, whereas the energy consumption pattern of USA is more complicated due to external factors.
\end{abstract}

Keywords - Energy, Equilibrium, Gradients, Non-Equilibrium Thermodynamics, Entropy

\section{Introduction}

Field of economics was essentially part of philosophy, before the industrial revolution. Religion, morality and ethics played a significant role in early theories. As a result, early economic thinking generally took into account the welfare of the common man instead of individualism. Economic thought evolved through feudalism, mercantilism and trade policies was part of economic thinking of classical economist s such as David Ricardo and John Stuart Mill before the arrival of Adam Smith's Wealth of Nation. The concern of distribution of wealth of the economy among rent, capital and labor was prominent during this period. The marginal revolution changes the models from the labor theory of value to utility of goods. Neoclassical economics was inclined towards Mathematics and Natural Sciences.

The changes in economics changed economic theories and vice versa. Later on, concepts of globalization had a profound impact on theories and its implementation. Economic thought have always accompanied changes in economy, just as changes in economic thought influenced change in economic policy. As modern economic thought deals with the problem of globalization and therefore the emergence of a world economy. In the seventeenth and eighteenth centuries, advances in natural sciences including that of circulation of blood in the human body were made. This concept was adopted to the economy as circular flow of income. This was pointed out by François Quesnay in his book Tableau 'Economique (1759) (Charles, 2003). Quesnay argued that agricultural surpluses were the basis for the circulation in economy in the form of rent, wages and expenses were the real economic movers. Income flowed from one sector to other. Based on Quesnay's analysis, it was argued that a "natural state" of the economy emerged when these income flows were in a state of "balance" (Vardi, 2012). There was balance of from one sector to other without expansion of contraction. The economy would continue in a stable manner once the natural state was achieve.

The Physiocrats began the anti-mercantilist movement (Neill, 1949). They argue against government's interference through price controls, taxes, and regulations. The economists were in favor of individual freedom which is supposed to result in economic growth. This was labeled as laissez faire or "let them do" (Landreth \& Colander, 2002). Although the Physiocrats were in some more detailed in their thinking, classical economics may be considered as the first modern school of economic thought. This arose in Great Britain within the latter a part of the eighteenth century. It was mainly developed by Adam Smith, David Ricardo, and John Stuart Mill. 


\section{General Equilibrium in Economics}

Classical economists had a strong sense of equilibrium. According to them, the economy would tend to a certain position even after the disturbance. Alfred Marshall used partial equilibrium analysis to explain a relationship between supply and demand (Marshall, 1920). However, Leon Walras used equal number of equations to describe equal number of unknown to elaborate the general equilibrium in economy (Walras, 2003).

The Walrasian model represented the first full recognition of the general equilibrium concept in the literature (Starr, 2011). It clearly stated that, for $N$ commodities, there are $N$ equations, for supply $S$ and demand $D$.

$$
S_{k}\left(p_{1}, p_{2}, \ldots, p_{N}\right)=D_{k}\left(p_{1}, p_{2}, \ldots, p_{N}\right)
$$

In the $N$ unknowns $p_{N}, n=(1,2, \ldots, N)$.

Later, Kenneth Arrow, Gerard Debreu (Arrow \& Debreu, 1954) and (Weintraub, 2011) used the fixed point theorem to demonstrate mathematically the existence of general equilibrium in economics. For their work in general equilibrium theorem Kenneth Arrow (1972) and Gerard Debreu (1983) receive d the Nobel memorial prizes in economics. What is meant by equilibrium in economics is that a point where the market supply equal demand. However, in this study (mostly based on Physics) equilibrium means static state and in certain cases it can be dynamic as well.

\section{Analogy between Economics and Physics}

Physics was developed by using the scientific approach. Economics tend to follow concepts in physics (and biology), and mathematics is used as a tool. Economics, focus on discussing the use of limited resources by people efficiently and effectively. Physics focus in discussing natural phenomena, the interaction between energy and matter. There are many economic concepts which have analogies with well-known concepts in physics. In the nineteenth century, Irving Fisher developed a set of mechanical analogy between economics and physics, invoking particle, force and displacement etc. Those are known as "fisher's translations" and given in Table 1 (Mirowski, 1991).

Table 1: Some of the analogies between mechanics and economics.

\begin{tabular}{l|l}
\hline \multicolumn{1}{c|}{ Mechanics } & \multicolumn{1}{c}{ Economics } \\
\hline A particle & An individual \\
\hline Displacement & Number of goods \\
\hline Force & Price \\
\hline Energy & Wealth \\
\hline Work or energy $=$ Force $\times$ Displacement & Utility = Marginal utility $\times$ Commodity \\
\hline Force is a vector & Marginal utility is a vector \\
\hline Forces are added by vector addition & Marginal utilities are added by vector addition \\
\hline Work and energy are scalars & Disutility and Utility are scalars \\
\hline $\begin{array}{l}\text { The total energy may be define as the integral with } \\
\text { respect to impelling force }\end{array}$ & $\begin{array}{l}\text { The total utility enjoyed by the individual is similar to the } \\
\text { integral with respect to marginal utilities }\end{array}$ \\
\hline $\begin{array}{l}\text { Equilibrium will be where impelling and resisting } \\
\text { force acting alone each axis will be equal }\end{array}$ & $\begin{array}{l}\text { Equilibrium will be where marginal utility and marginal } \\
\text { disutility along each axis will be equal }\end{array}$ \\
\hline
\end{tabular}

Fisher's explanation is best to begin an insight of the neoclassical model. And his notion has persisted as the teaching model long after the notion of Walras, which promotes the general equilibrium in economics. In Addition to mechanical analogy with economics, there are some more. The table 2 given below represent some of the Themodynamical analogy with economics (Mirowski, 1991). 
Table 2: Some of the analogies between thermodynamics and economics.

\begin{tabular}{l|l}
\hline \multicolumn{1}{c|}{ Thermodynamics } & \multicolumn{1}{c}{ Economics } \\
\hline Helmholtz free energy $(-F)$ & Wealth $(W)$ \\
\hline Energy $(E)$ & Utility $(U)$ \\
\hline Temperature x entropy $(T S)$ & Surplus $(\psi)$ \\
\hline Chemical potential $(\mu)$ & Price $(\beta)$ \\
\hline Number of identical particles $(N)$ & Number of goods $(N)$ \\
\hline
\end{tabular}

The concepts in economic and physics have a similarities. This study shows that the economical equilibrium is not a forgone conclusion. It can also fluctuate around the equilibrium, such as the thermo dynamical equilibrium fluctuate around its equilibrium position. This concept is discussed in Non- Equilibrium Thermodynamics (NET).

Furthermore in Statistical Mechanics each microstate $s$ is weighed by energy $E_{s}$ of a system, which is in equilibrium with a heat reservoir by the factor $e^{-E_{S} / T}$ and the partition function can be defined as follow

$$
Z=\sum_{\text {states }} e^{-E_{S} / T}
$$

From the above equation the free energy $F$ is defined via

$$
Z=e^{-F / T}
$$

So that,

$$
F=-T \ln Z
$$

Where $F$ Helmholtz Free Energy gives the thermodynamic properties of the physical system. The number of economic states were necessary to make an analogy to economics. Moreover, an economic system will try to maximize utility or wealth. Whereas, a physical system will seek to minimize free energy (Saslow \& Wayne, 2000).

Consider an economics microstate $s$ with wealth $W_{s}$ and $T$ Economic temperature. Then the partition function can be defined follows,

$$
Z=\sum_{\text {states }} e^{W_{s} / T}
$$

And the utility $U$

$$
Z=e^{U / T}
$$

So that

$$
U=T \ln Z
$$

By considering this equations, the Boltzmann like relation can be obtained

$$
U=W+T S
$$

Where $s$ is economic entropy for an economy.

Ultimately, it can be showed that the theory of fluctuation about economic equilibrium in analogy to the theory of fluctuations about thermodynamic equilibrium. The fluctuations $\delta N$ in the number of particles $N$ satisfy

$$
\overline{(\delta N)^{2}}=T\left(\frac{\partial N}{\partial \mu}\right) \quad \text { (In thermodynamics) }
$$

Where, $\mu$ is the chemical potential. In economy, fluctuations $\delta N$ in the number of goods $N$ have a mean square average. Which satisfy

$$
\overline{(\delta N)^{2}}=-T\left(\frac{\partial N}{\partial \beta}\right) \quad \text { (In economics) }
$$


Where, $\beta$ is the price. This equation predicting that fluctuations increases when $(\partial N / \partial \beta)$ increases for a fixed $T$. Similarly fluctuations increases as $T$ increases for a fixed $(\partial N / \partial \beta)$ (Agarwal \& Eisner, 1994). In order to have deeper understanding of economics, it is helpful to be familiar with the concepts of NET.

\section{Non-Equilibrium Thermodynamics (Net) and Economics}

$N E T$ is a branch of thermodynamics that which deals with non-equilibrium state variables which is often encountered in nature. A system it can be able to self-organize and sustain far from equilibrium. This can be understand by the theory of "dissipative structures" (Capra, 1996). Dissipative structures are open systems, they need a continuous input of free energy from the environment in order to maintain the system. That is flux of energy, into and out of a dissipative structure, which leads towards self-organization and ultimately the ability to function at a state of non-equilibrium.

Natural systems such as economical systems are also self-organizing dissipative structures, they take in and give off energy from the environment in order sustain the processes and in doing so function at a state of non-equilibrium (Pierce, 2002). Although the natural systems maintain a state far from equilibrium they are still described by the second law of thermodynamics. Like all physiochemical systems, natural systems are always increasing their entropy due to the overwhelming drive towards equilibrium. The Second Law therefore argue that all highly ordered, far from equilibrium, complex systems necessarily develop and grow at the expense of increasing disorder at higher levels in the surroundings (Schneider \& Kay, 1994). The economy is such highly ordered, complex, dynamic system. It is also an open system. The economic systems have moderate scarcity as their condition. But scarcity is not the primary condition for an economy. What economy rest on are gradients. They depend on the finding ways of keeping material flow at a suitable rate. Like other NET systems, economic systems are not isolated but are open systems.

Economy go towards the equilibrium. This seems obvious as long as we keep in mind that markets and economies are not themselves closed systems, ultimately depend upon the ultimate "nonrenewable" resources the sun. A market, like an organism, depend s upon external source for their complexity maintaining gradient reduction activities. Economics, like the ecosystem, expand via the natural weal th of the gradients around them. However, the failure of profitable gradient promotes to become markets, is similar to the failure in an ecology of grasslands go through a process to become a forest. New realizations and innovations in the marketplace, like the evolution of new organism able to make use of old resources in new ways or to find altogether new ones to exploit. Likewise, the entirely stable ecosystem would be no economy at all. Economics and market like organisms and ecosystems are metastable non-equilibrium systems (Sagan \& Schneider, 2006).

The classical economy based their theories on a notion of the circulation process of production and consumption. The major assumption in a circular flow is that resources are limitless, which is clearly in violation of the second law of thermodynamics. The economic process consists of an eternal transformation of low entropy into high entropy. That is, into irrevocable waste or into pollution. Increasing economic activity requires more and more natural resources such as energy and materials. A limited resources view is necessary condition for standard economic theory but needs to be understood in the wide context of non-equilibrium markets and economies that find new ways to grow, essentially upon gradients. So the thermodynamic thinking about the economy is practical as well as theoretical.

\section{Energy and Economics}

Despite the fact that economies are not stable but metastable dissipative systems which are normally discussed in NonEquilibrium Thermodynamics. Like organisms and ecosystems, they tend to grow by exploiting gradients (Sagan \& Schneider, 2006). However, the concept of entropy, which is important in economics, is difficult to quantify (Roegen, 1971). Thus, energy consumption is used as a proxy for the measurement of entropy (Wijeratne, 2006). Hence, taking into account of thermodynamical concerns a model for energy consumption in an economy is proposed in figure 1 .

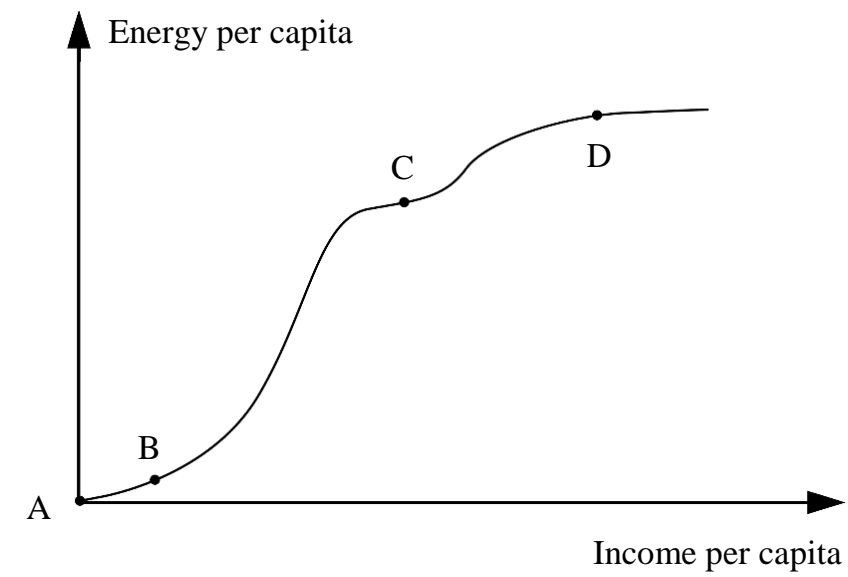

Figure 1: Energy per capita vs. income per Capita of Sri Lanka 
In addition, the economical state can fluctuate around a point where near equilibrium (i.e., point B) where the point A is equilibrium state. And also economy can fluctuate around a point while situated much far from the equilibrium (i.e., point $C$ and $D$ ) as shown in figure 1 . To sustain it at much far from the equilibrium state (i.e., point $D$ ), its need to degrade much more energy and materials. An economical state such as shown in point $\mathrm{C}$ is relatively much more stable. The reason for this behavior is the economical fluctuations around that point $\mathrm{C}$ is relatively less compared to other states. This is a desired level of energy consumption compatible with the concept of sustainability, which is desired goal of this study. Energy consumption in Sri Lanka can be shown in different ways. Figure 2 gives total primary energy consumption as a function of the year.

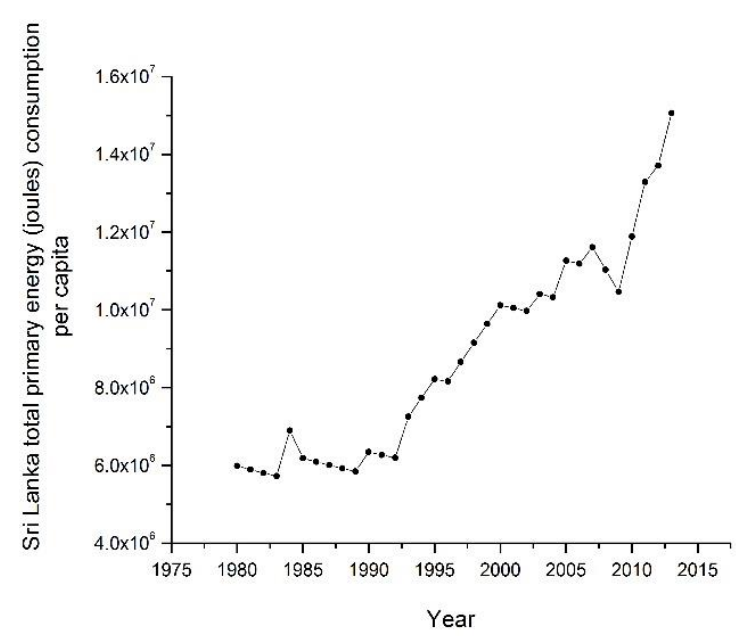

Figure 2: Sir Lanka total primary energy consumption Per capita from 1980 to 2013

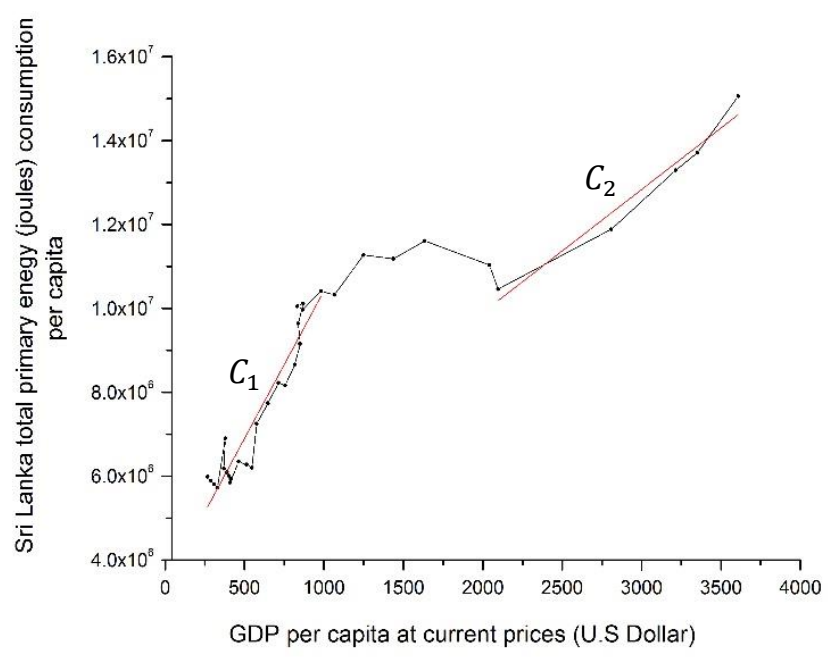

Figure 3: GDP Per capita at current prices vs. Sir Lanka total primary Energy consumption per capita

Energy consumption in Sri Lanka can be shown in different ways. Figure 2 gives total primary energy consumption as a function of the year. However, figure 3 gives the Per Capita GDP as a function of Sri Lankan Which have similar behavior as suggested by the model given (see figure 1) in this study. There is a clear shift in the pattern (i.e., point A to B) of total primary energy consumption (Anon., 2018) with respect to Per Capita GDP (Anon., 2018) within this time period, Sri Lankan total primary energy consumption increased more or less while the Per Capita GDP increases suddenly. According to the fitted line plots $\left(C_{1}\right.$ and $\left.C_{2}\right)$, relationship between Sri Lankan total primary energy consumption per capita and Per capita GDP can be expressed as follows.

$C_{1}: Y=7030.98009 X+3.38698 \times 10^{6}$

$C_{2}: Y=2932.16851 X+4.03829 \times 10^{6}$

Where, $Y$ : Sri Lanka total primary energy (joules)consumption per capita.

\section{$X$ : GDP per capita at current prices.}

It is necessary to fulfill the basic needs of a human being which are essential. Secondary, once a certain level of consumption and satisfaction is achieved, then there is the discretion to choose the economic activity. Therefore, the rate of energy consumption tend to be lower as there is a process of selection in ones economic activity. However, this may not be true in countries where energy is abundantly available.

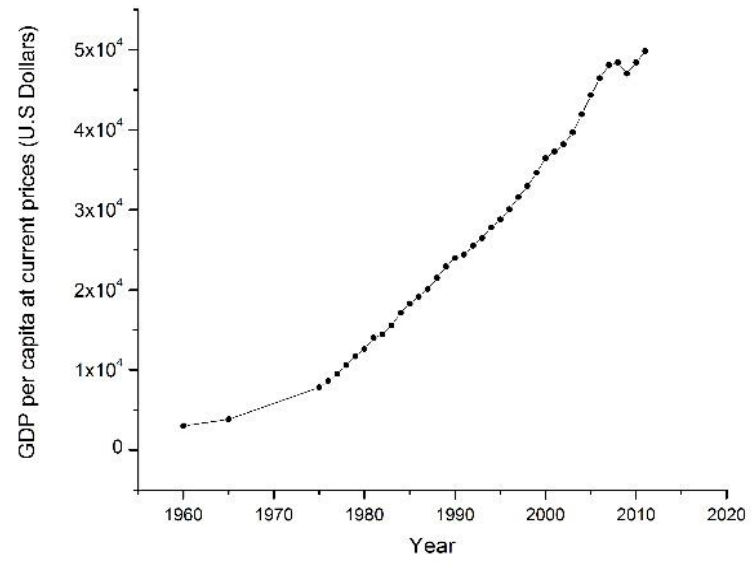

Figure 4: GDP Per capita at current prices of USA from 1960 to 2017

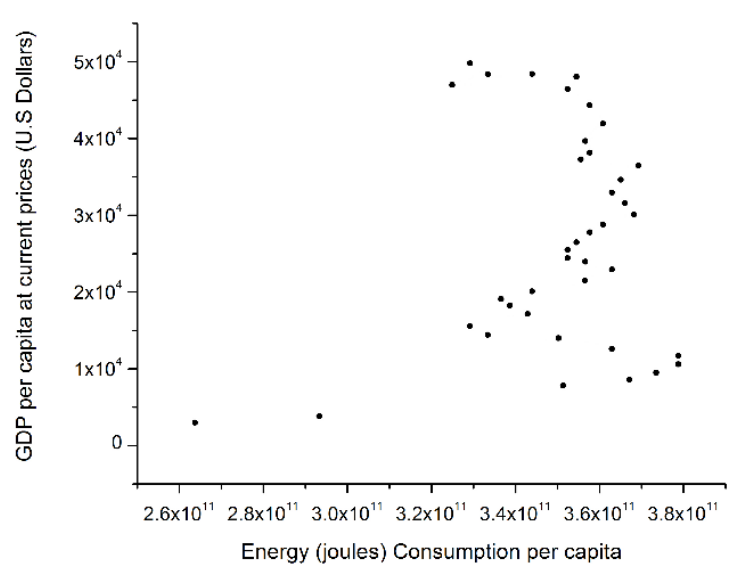

Figure 5: GDP Per capita at current prices vs Energy consumption Per capita Of USA 
Nevertheless, the energy consumption patterns for USA is different from the model proposed by us. The GDP per capita (Anon., 2018) and energy consumption (Ratner \& Glover, 2014) for USA economy is given above in figure 4 and figure 5 , respectively. This can be explained by the reasons given below.

\section{Mercantilism, Trade Agreements and Outsourcing}

Mercantilism is a method of using of power to increase exports while collecting precious metals instead (Irwin, 1991).This process was dominant in the nineteenth century. This sits well with the present concept of American exceptionalism, where weaponizing the dollar is also an important concept. However, if the American manufacturing sector is concerned, it had drop from 53 percent of economy in 1965 to roughly one fifth of the economy in 1996. This process had been accelerated with trade agreements entered into by America which tends to hollow out the manufacturing sector of the economy. These changes in the economy have been aided by the increasing automation of the economy. The process of out sourcing (Iqbal \& Munir, 2013) and the dollar as a global currency has resulted in large trade deficits which a threat to long term sustainability of USA economy. It is also clear the USA has been in continuous process of reduction of per capita energy consumption while increasing its per capita income.

\section{Conclusion}

It is desirable to consider economical systems from energy consumption perspective. The energy consumption pattern in USA is different from that proposed by our model, which may resemble more like that of Sri Lanka, if the USA economy is to be more inward looking. The key to sustainability of economy is the level of energy (and material) consumption in the system while minimizing environmental impacts.

\section{References}

Agarwal, B. K. \& Eisner, M., 1994. Statistical Mechanics. New Delhi: Wiley Eastern Limited.

Anon., 2018. Bank, W.. [Online]

Available at: https://data.worldbank.org/indicator/NY.GDP.MKTP.CD?locations=LK

Anon., 2018. Bank,W.. [Online]

Available at: https://data.worldbank.org/indicator/NY.GDP.PCAP.CD?locations=US

Anon., 2018. Mundi, Index. [Online]

Available at: https://www.indexmundi.com/energy/?country=lk\&product=total-primary-energy\&graph=consumption [Accessed 88 2018].

Arrow, K. J. \& Debreu, G., 1954. Existence of an Equilibrium for a Competitive Economy. Econometrica, Volume 22, p. 265.

Capra, F., 1996. The Web of Life. New York: Anchor.

Charles, L., 2003. The visual history of the Tableau Economique. European Journal of the History of Economic Thought, Volume 10, pp. 527-550.

Iqbal, Z. \& Munir, A., 2013. Outsourcing:A Review of Trends Winners and Losers and Future Directions. International Journal of Business and Social Science, Volume 4, pp. 91-107.

Irwin, D. A., 1991. Mercantilism as Strategic Trade Policy: The Anglo-Dutch Rivalry for the East India Trade. Journal of Political Economy, 99(6), pp. 1296-1314.

Landreth, H. \& Colander, D. C., 2002. History of Economic Thought. 4, illustrated ed. Boston: Houghton Mifflin Harcourt.

Marshall, A., 1920. principles of economics. Palgrave classics in economics. Eighth Edition ed. London: Macmillan and Co.

Mirowski, P., 1991. More Heat Than Light: Economics as Social Physics, Physics as Nature's Economics. illustrated ed. Cambridge: Cambridge University Press.

Neill, T. P., 1949. The Physiocrats' Concept of Economics. The Quarterly Journal of Economics, 63(4), pp. 532-553.

Pierce, S. E., 2002. Non-Equilibrium Thermodynamics: An Alternate Evolutionary Hypothesis. s.1.:Crossing Boundaries an interdisciplinary journal.

Ratner, M. \& Glover, C., 2014. U.S. Energy: Overview and Key Statistics, s.1.: congressional research service .

Roegen, N. G., 1971. The Entropy Law and the Economic Process. s.1.:Harvard University Press .

Sagan, D. \& Schneider, E. D., 2006. Into the cool. New Delhi: Prentice Hall of India. 
Saslow, M. \& Wayne, 2000. An Economic Analogy to Thermodynamics. American Journal of Physics, Volume 67, pp. 1239-1247.

Schneider, E. \& Kay, J., 1994. Life as a manifestation of the second law of thermodynamics. Elsevier, Volume 19, pp. 25-48.

Starr, R. M., 2011. General equilibrium theory An Introduction. Cambridge: Cambridge University Press.

Vardi, L., 2012. The physiocrats and the world of the Enlightenment. Cambridge: Cambridge University Press.

Walras, L., 2003. Elements of Pure Economics: Or the Theory of Social Wealth. Reprint ed. London: Routledge.

Weintraub, E. R., 2011. Retrospectives: Lionel W. McKenzie and the Proof of the Existence of a Competitive Equilibrium. Journal of Economic Perspectives, Volume 25, pp. 1-5.

Wijeratne, A. T., 2006. Abuddhist's veiew on sustainability. Pannipitiya, Sri Lanka: Author. 